TITLE:

\title{
Variation in Spatial Cohesiveness in a Group of Japanese Macaques (Macaca fuscata)
}

\section{$\operatorname{AUTHOR}(\mathrm{S})$ :}

Sugiura, Hideki; Shimooka, Yukiko; Tsuji, Yamato

\section{CITATION:}

Sugiura, Hideki ...[et al]. Variation in Spatial Cohesiveness in a Group of Japanese

Macaques (Macaca fuscata). International Journal of Primatology 2011, 32(6): 1348-1366

ISSUE DATE:

2011-12

URL:

http://hdl.handle.net/2433/147051

\section{RIGHT:}

(c) Springer Science+Business Media, LLC; The final publication is available at www.springerlink.com; This is not the published version. Please cite only the published version.; この論文は出版社版でありません。引用の際には出版社版をご確認ご利用くだ さい。 


\section{Variation in spatial cohesiveness in a group of Japanese macaques (Macaca fuscata)}

Short title: Group cohesiveness in Japanese macaques

Authors:

\section{Hideki Sugiura}

Primate Research Institute, Kyoto University, Inuyama, Aichi 484-8506, Japan

Current address: Wildlife Research Center, Kyoto University, Kyoto, 606-8203, Japan

Yukiko Shimooka

Primate Research Institute, Kyoto University, Inuyama, Aichi 484-8506, Japan

Current address: Department of Natural \& Environmental Science

Teikyo University of Science, 2525 Yatsusawa, Uenohara, Yamanashi 606-8502, Japan

Yamato Tsuji

School of Agriculture and Life Sciences, University of Tokyo, Bunkyo, Tokyo 113-0033, Japan

Current address: Primate Research Institute, Kyoto University, Inuyama, Aichi 484-8506, Japan

Correspondence:

Hideki Sugiura

Wildlife Research Center, Kyoto University, 2-24 Tanaka-Sekiden-cho, Sakyo, Kyoto, 6068203, Japan

E-mail: sugiura.hideki.7s@kyoto-u.ac.jp

Telephone: $+81-75-771-4379$

Fax: $+81-75-771-4394$ 


\section{Abstract}

The spatial cohesiveness of a group is an important element that characterizes the social structure of group-living species. Moreover, remaining cohesive is crucial if individuals are to coordinate their activities and reach collective decisions. We measured interindividual spacing in a group of wild Japanese macaques (Macaca fuscata) to assess the spatial cohesiveness of a social group quantitatively. We used simultaneous focal animal sampling, with two observers recording individuals' locations with a global positioning system (GPS) during 3 seasons. Interindividual distances differed among seasons; they were short in autumn (mean $\pm \mathrm{SD}$ : $25.6 \pm 20.1 \mathrm{~m})$, intermediate in winter (mean $\pm \mathrm{SD}: 46.3 \pm 35.7 \mathrm{~m})$, and long in summer (mean \pm SD: $62.3 \pm 47.1 \mathrm{~m})$. Measurements taken in summer revealed extremely wide spacing (maximum: $1225 \mathrm{~m}$ ), suggesting subgrouping. Distances also varied with activity during each season; they were short during resting and grooming, intermediate during foraging, and long during moving. Group cohesion was also influenced by food distribution. More group members were $\leq 20 \mathrm{~m}$ of the focal individual during foraging on clumped food than foraging on scattered food in each season, and the group foraged on clumped food most frequently in autumn. Individuals were also likely to aggregate at resting/grooming sites and clumped food patches and to disperse when moving within a day. These results demonstrate that Japanese macaques show considerable variation in spatial cohesiveness both within short time periods,.eg. 1d, and among seasons, and that they adjust group cohesiveness flexibly depending on the food conditions and foraging tactics.

Keywords: dispersion, GPS, group spread, interindividual spacing, seasonal variation

\section{Introduction}


The spatial cohesiveness of a group is an important element of the social structure of groupliving animals. Social structure has been described in terms of the cohesiveness or interindividual spacing between group members, and can be characterized by their degree of fission-fusion dynamics (Aureli et al., 2008). Where the size and composition of a group changes by temporary fission and fusion of smaller and independent subunits (called subgroups or parties) frequently, according to the need and distribution of resources, such species can be said to show high fission-fusion dynamics. In contrast, where species do not exhibit obvious fission-fusion of subunits, and group members usually remain close and move together, they can be said to show low fission-fusion dynamics (Aureli et al., 2008). The degree of spatial cohesiveness is important for group coordination. Individuals staying close to other group members are likely to take the same travel route and visit the same food patches. In contrast, individuals who maintain a variable distance, and are occasionally far from other group members, have the freedom to take a different route and visit different food patches from those of other group members (Jacobs, 2010). The degree of spatial cohesiveness can also influence communication within a group, which is essential for collective decisions. Individuals in a spatially cohesive group can communicate "globally" with all group members. In contrast, individuals in a less cohesive, spatially spread group can only communicate "locally" with some of the group members (Conradt \& Roper, 2005).

Two major factors have been considered to affect group cohesiveness: predation avoidance and intragroup feeding competition. The maintenance of close proximity to others facilitates predation avoidance (Hamilton, 1971), but hinders foraging due to competition from other group members (Wrangham, 1980). It has been suggested that groups tend to become cohesive when proximity confers a greater benefit in the presence of predators (Chivers et al., 1995), or that proximity may incur a greater cost when food resources are scarce (Janson, 1988). Thus, group-living animals need to make a trade-off between costs and 
benefits. This trade-off may be mediated by adjusting interindividual spacing (Aureli et al., 2008).

Group cohesiveness in primates has been studied mostly in species that show high fission-fusion dynamics, such as the Atelinae subfamily (Bezanson et al., 2008; Shimooka, 2003; Strier, 1989, 1992; Symington, 1988), chimpanzees (Pan troglodytes) (Goodall, 1986; Nishida, 1968), and Hamadryas baboons (Papio hamadryas) (Kummer, 1971). In the Atelinae the nature of the food patch has been suggested to influence the party size (Strier, 1992; Symington, 1988). Food condition and the presence of estrous females have been suggested to influence party size among chimpanzees (Hashimoto et al., 2003; Matsumoto-Oda et al., 1998). In contrast to studies on species showing high fission-fusion dynamics with distinct and countable subunits, group cohesiveness has rarely been quantified in species showing low fission-fusion dynamics (Boinski, 1987; Janson, 1990a, 1990b; Robinson, 1981). In addition, little is known about the extent of variation in spatial cohesiveness within a species or group.

A simple model of the spatial distribution of individuals for species that show low fission-fusion dynamics assume that inter-individual distances are homogeneous, and that group dispersion is constant (e.g., Waser, 1984; Whitesides et al., 1988). Such a model is useful for understanding group-level behaviors, such as mixed species association, intergroup encounters, and the localization of a group, but is not useful for understanding changes in interindividual spacing. Here, we provide the first quantitative data of interindividual distances collected using GPS in the wild. Most previous studies of interindividual spacing within a group have focused on narrow ranges, such as distance to the nearest neighbor or numbers of individuals within close proximity (Cowlishaw, 1999). Each observer in our study followed a focal individual independently, which enabled them to measure long-range distances accurately with a GPS. This simple and reliable method could be applied to other 
populations and species, and may be used for direct comparison between populations and species.

Japanese macaques (Macaca fuscata) form female-bonded groups, with females residing in the natal group and males emigrating from the natal group during adolescence (Yamagiwa \& Hill, 1998). The animals have a linear dominance hierarchy based on kin relationships among resident females (Hill \& Okayasu, 1995). They occupy seasonal habitats (Tsuji \& Takatsuki, 2004), and their activity varies among seasons (Agetsuma \& Nakagawa, 1998). Japanese macaques are thought to show low fission-fusion dynamics with a stable membership (Koyama, 1967). However, Japanese macaque group cohesiveness can be variable and subgrouping - in which a group temporarily splits into $\geq 2$ independent subunits — is occasionally reported (Izawa, 2009; Sugiyama \& Ohsawa, 1982). Sueur et al. (2010) also reported short-term fission-fusion in other Macaca spp.

We hypothesized that the degree of interindividual spacing would change within short time periods, e.g., $1 \mathrm{~d}$, or among seasons or both. First, we describe the general pattern and variation of interindividual spacing in our population. We then explore factors that may influence the variability we found. At the level of the dyad, we explored how seasonality, kinship, and activity type related to inter-individual distance. At the level of the individual, we explored the possibility that food type affected the proximity of group members around the focal individual.

\section{Methods}

Subjects

We studied the A group of wild Japanese macaques on Kinkazan Island, northern Japan 
$\left(38.30^{\circ} \mathrm{N}, 141.56^{\circ} \mathrm{E}\right.$; elevation 0 - $445 \mathrm{~m}$ a.s.1.). The members of A group have been individually identified since 1983 and are well habituated to human observers (Sato, 1988). We knew the maternal lineage for all natal members of this group, but not the paternal lineage. We defined kin as relatedness $(r) \geq 1 / 4$ and non-kin as $r<1 / 4$, based on the relatedness threshold for nepotistic aiding (Chapais et al., 1997). Kin dyads included motherdaughter dyads and maternal sisters. We determined female dominance rank using agonistic interactions between 2 individuals, including both severe and mild aggressions (Hill \& Okayasu, 1995). These interactions had been accumulated during long-term study on this group and we also recorded all agonistic interactions observed by ad libitum sampling during the study period. Dominance rank was stable throughout the study period. No natural predators of these monkeys are present on the island, and hunting is forbidden by law and religion. The forest is relatively open, and we obtained adequate GPS signals for $86 \%$ of our observation time. The details of the subjects and their habitat have been described elsewhere (Tsuji et al., 2006; Tsuji \& Takatsuki, 2004).

We collected data in 3 seasons: autumn, October 16 - November 8, 2003; winter, February 10 - 22, 2004; and summer, July 6 - 23, 2004. We observed 30 (4 kin [1 mother-daughter, 3 maternal sisters], 26 non-kin) of 45 possible pairs in autumn, 29 (4 kin [4 maternal sisters], 25 non-kin) of 36 possible pairs in winter, and 21 (1 kin [1 maternal sisters], 20 non-kin) of 21 possible pairs in summer. During the study period, the subject group was composed of $31-39$ individuals: 17 adult females ( $\geq 5 \mathrm{yr}$ old), $5-13$ adult males ( $\geq 5 \mathrm{yr}$ old), $2-5$ juvenile females ( $1-4$ yr old), $2-4$ juvenile males $(1-4$ yr old), and $5-8$ infants ( $<1$ yr old). The monkeys ranged over $c a .3 \mathrm{~km}^{2}$ during the study period.

\section{Data Collection}


Two observers each followed an anestrous focal adult female, using focal animal sampling.

We excluded estrous females because they tend to stay on the periphery of the group to mate with low-ranking or non-troop males (Hayakawa, 2007). We chose 10, 9, and 7 females of various dominance ranks as subjects in autumn, winter, and summer, respectively. Seven of these animals were common to all 3 study periods. To examine the effect of kinship on interindividual distance, we gave priority to the limited number of females with adult kin female(s). The dominance rank order of the subject females did not differ from that of nonfocal females (Mann-Whitney $U$ test, autumn: $U=30, n_{1}=10, n_{2}=7, p=0.63$; winter: $U$ $=33, n_{1}=9, n_{2}=8, p=0.77$; summer: $U=28, n_{1}=7, n_{2}=10, p=0.49$ ).

We did not observe 15 pairs in autumn because some of the subject females entered estrous. We omitted 5 nonkin pairs from winter observations due to the limitations of our observation period. We also omitted a mother-daughter pair that we observed in autumn, because we could not find them for most of the winter study period. In summer, we reduced the numbers of subjects and pairs because we had less observation time than in other seasons owing to the difficulty of finding and following the group, which was usually widely distributed and moved fast. It was particularly difficult to find kin pairs under such conditions. The mean observation times per pair were $7.3 \pm 0.1($ mean $\pm \mathrm{SE}) \mathrm{h}, 9.3 \pm 0.1 \mathrm{~h}$, and $4.4 \pm 0.1$ $\mathrm{h}$ in autumn, winter, and summer, respectively. The mean observation times per individual were $33.1 \pm 5.0 \mathrm{~h}, 31.9 \pm 3.5 \mathrm{~h}$, and $29.1 \pm 1.3 \mathrm{~h}$ in autumn, winter, and summer, respectively.

Each observation session was composed of $4 \mathrm{~h}$ of simultaneous observation, during which we recorded the focal individual's activity every $1 \mathrm{~min}$ by instantaneous sampling. We classified activities into 5 categories: grooming, resting, foraging, moving, and agonistic interaction. Foraging activities included searching for, handling, and processing food. Moving referred to continuous movement for $>1 \mathrm{~m}$. Grooming included grooming other individuals, being groomed, or self-grooming. We defined resting was defined as an inactive state without 
foraging, moving, or grooming. Agonistic interactions included aggression toward others (hitting, grabbing, biting, chasing, and threatening), aggression received, and submissive behavior toward aggressors.

We recorded the number of individuals $\leq 20 \mathrm{~m}$ of each focal individual every 5 min by instantaneous sampling. We excluded infants $<1$ yr of age because they were usually dependent on their mothers and other individuals. We excluded data when visibility was $<20$ m.

We measured location, time, and positional dilution of precision (PDOP, an index of position accuracy) using a GPS receiver (IPS-5100; Sony, Tokyo, Japan or GPS Pathfinder Pocket; Trimble, Sunnyvale, CA, USA). We recorded GPS data every $1 \mathrm{~s}$ on a hand-held computer (200LX or iPAQ h2210; Hewlett-Packard, Tokyo, Japan). We usually remained within a horizontal distance of $10 \mathrm{~m}$ from the focal individual and considered the position of the observer to be that of the focal individual. We did not use GPS location data recorded when we had lost the focal individual or when the horizontal distance to the focal individual was $>15 \mathrm{~m}$ for $>1 \mathrm{~min}$.

Analysis

We converted location data to rectangular coordinates using the Universal Traverse Mercator (UTM) projection. We then calculated the horizontal distance between the 2 focal individuals. To remove large location errors, we used only measurements with PDOP smaller, i.e., better than 6.5 with 3-dimensional fix (D'Eon \& Delparte, 2005). We chose location data with the smallest PDOP within a -15 -s to +15 -s window from the sampling time (at 15 min intervals). When this process resulted in two or more coordinates with equally low PDOP, we chose the data closer to sampling time. On occasion, 3 observers each simultaneously followed a focal 
individual. In these cases, we used the distance between each pair combination, e.g., $\mathrm{A}-\mathrm{B}, \mathrm{A}$ $-\mathrm{C}, \mathrm{B}-\mathrm{C}$, as independent data. Analyses employed the distance between 2 individuals sampled at a minimum of 15-min intervals (sampling interval was extended by $5 \mathrm{~min}$, i.e., 20 , $25, .$. min, due to loss of the focal animal or unreliable GPS positions).

Interindividual distances during summer were extremely large $(0-1225 \mathrm{~m})$, suggesting that subgrouping occasionally occurred. To determine the criteria at which subgrouping occurred, we performed nonlinear regression using 2-process gamma distributions based on the method described by Sibly et al. (1990). We applied a single gamma model, $\mathrm{y}=\mathrm{c} \times \mathrm{x}^{(\mathrm{b}-1)}$ $\times \mathrm{e}^{-\mathrm{ax}}$, where $\mathrm{y}$ is frequency, $\mathrm{x}$ is distance, and $\mathrm{a}, \mathrm{b}$, and $\mathrm{c}$ were constants. We then applied a 2process model, $\mathrm{y}=\mathrm{c}_{1} \times \mathrm{x}^{(\mathrm{b} 1-1)} \times \mathrm{e}^{-\mathrm{a} 1 \mathrm{x}}+\mathrm{c}_{2} \times \mathrm{x}^{(\mathrm{b} 2-1)} \times \mathrm{e}^{-\mathrm{a} 2 \mathrm{x},}$, where $\mathrm{a}_{1}, \mathrm{~b}_{1}, \mathrm{c}_{1}, \mathrm{a}_{2}, \mathrm{~b}_{2}$, and $\mathrm{c}_{2}$ are constants. We tested whether the goodness-of-fit of the 2-process model improved over the single-process model. We set the distance criteria at the intersection of the 2 curves, i.e., where the 2 processes occurred with the same probability. We included some data as nonsubgrouping, where 2 focal animals were separated by a distance greater than the criterion for a short period of time. To determine the criteria of such short-term separation, we conducted bout criteria analysis (Sibly et al., 1990; Slater \& Lester, 1982). We used the interindividual distance data of non-subgrouping for seasonal comparisons because our objective was to assess seasonal variations in the usual interindividual distance within a group.

To analyze the relationship between distance and activity type, we classified the activities of the 2 focal females as "both resting or grooming," "both foraging," "either or both moving," and "other combinations." To represent relatively long and stable activity around the sampling time (at 15-min intervals), we analyzed activities observed during 5-min periods, i.e., 5 instantaneous sampling points of activity at $-2,-1,0$ (the same time), +1 , and +2 min from the sampling time. We defined an activity type as "both resting or grooming" and "both foraging" when each focal female in a pair exhibited these behaviors at 4 or 5 of the 
5 sampling points $(\geq 80 \%)$. We defined an activity as "either or both moving" when at $\geq 1$ individual was moving at $\geq 3$ sampling points $(\geq 60 \%)$. In this case, the activity of the other individual was arbitrary (one individual was moving in $80 \%$ of cases, both individuals were moving in $20 \%$ of cases). We relaxed the criterion for this category because movement did not last as long as resting, grooming, or foraging. We defined any combination of activity other than these 3 categories as "other combinations."

To analyze the activity budget and the number of individuals within close proximity in relation to food type, we used all data sampled at 1-min and 5-min intervals, respectively, to calculate means for each individual. Because these analyses were not accompanied by location data, we used all available data, regardless of location data reliability at sampling. This process yielded data characterizing the general activities of the animals during each season. We classified foods as clumped or scattered. Clumped foods included trees, the shrub Berberis thunbergii, and the herb Perilla frutescens, which form large clumped patches. Scattered foods included shrubs (except Berberis thunbergii), herbs (except Perilla frutescens), vines, fungi, animals, and seaweeds.

We performed all statistical analyses using generalized linear mixed models with SAS software (version 9.2; SAS, Cary, NC, USA). We treated pairs of individuals as random effects for analyses in which we calculated dependent variables from these pairs (analyses of interindividual distance and of the number of proximate individuals by distance categories). We treated individuals as random effects for analyses in which dependent variables were calculated from a single individual (analysis of number of proximate individuals during foraging). We used a gamma distribution for analyses of interindividual distance and a Poisson distribution for analysis of the number of individuals around the focal individual.

\section{Results}


General Pattern of Interindividual Distance and Subgrouping

The interindividual distance curves of all seasons were skewed to the right (Fig. 1). Of 4 basic continuous distributions, normal, log-normal, Weibull, and gamma, a gamma distribution showed the best fit in autumn and winter. The observed distributions did not differ significantly from a gamma distribution (Kolmogorov-Smirnov test, autumn $D=0.036, N=$ $665, p>0.2$; winter, $D=0.037, N=996, p>0.1)$. We regarded all data in autumn and winter as non-subgrouping.

The overall distribution of summer showed extremely long distances (maximum, 1225 m; Fig. 1C) and apparently deviated from a single gamma distribution. These long distances suggest that subgrouping occurred in summer. Thus, we conducted nonlinear regression analysis, assuming two gamma distribution processes. The 2-process model significantly fit the actual distribution $\left(F_{5,69}=128.6, p<0.0001\right.$; Fig. $\left.1 C\right)$, and the goodness-of-fit was significantly improved from the single-process model $\left(F_{3,69}=13.3, p<0.0001\right)$. Based on the 2-process model, we set the distance criterion as $114 \mathrm{~m}$, which was the intersection of the 2 gamma curves. We classified all data in which the interindividual distance was $<114 \mathrm{~m}$ in summer as non-subgrouping.

Our identification of subgrouping above is based only on distance, and we do not consider the time individuals spend apart at different distances. We therefore looked at the sequence of distances over time and analyzed the duration of the period when the distance between the 2 was $\geq 114 \mathrm{~m}$ using bout criteria analysis. We measured durations from the time the distance was $\geq 114 \mathrm{~m}$ and obtained 73 time bouts upon which we conducted bout criteria analysis. The 2-process model assumed that 2 exponential distributions significantly fit the actual distribution $\left(F_{3,19}=60.7, p<0.0001\right)$; the goodness-of-fit was significantly improved 
over the single-process model $\left(F_{2,19}=15.5, p=0.0001\right)$. The bout criterion was $33 \mathrm{~min}$. There were 70 bouts in which the distance was $\geq 114 \mathrm{~m}$ for $<33 \mathrm{~min}$; we therefore classified these as non-subgrouping. There were 19 bouts in which the distance was $\geq 114 \mathrm{~m}$ for $\geq 33 \mathrm{~min}$; we classified these as subgrouping. There were 10 sequences during which the distance was $\geq 114$ m but whose durations, whether $<33$ or $\geq 33$ min, were unknown because of the start or end of observations or unreliable GPS positions. We classified these bouts as unknown.

Using these criteria, we classified the data for summer as non-subgrouping $(\mathrm{N}=193$, 63.9\%), subgrouping $(\mathrm{N}=101,33.4 \%)$, or unknown $(\mathrm{N}=8,2.7 \%)$. Figure 1D shows the distribution of non-subgrouping in summer. The observed distribution did not differ significantly from a gamma distribution (Kolmogorov-Smirnov test, $D=0.029, N=101, p>$ $0.5)$.

Among the non-subgrouping data, mean distances were shortest in autumn (mean $\pm \mathrm{SD}$, 25.6 $\pm 20.1 \mathrm{~m}$; maximum, $172 \mathrm{~m}$; Fig. 1A), intermediate in winter (mean $\pm S D, 46.3 \pm 35.7 \mathrm{~m}$; maximum, 262 m; Fig. 1B), and longest in summer (mean \pm SD, 62.3 $\pm 47.1 \mathrm{~m}$; maximum, 253 m; Fig. 1D). For the following analysis of interindividual distances for seasonal comparison, we used these non-subgrouping data to examine the seasonal variations in the usual interindividual distances.

Factors Affecting Interindividual Distance

We constructed a factorial model to examine the effects of season, activity, kinship, and interaction between season and activity. This analysis did not include interactions with kinship (season $\times$ kinship or activity $\times$ kinship) because the number of kin pairs was insufficient to analyze these effects. 
The effect of season was significant $\left(F_{2,41}=29.4, p<0.0001\right)$, and interindividual distance was smallest in autumn, intermediate in winter, and largest in summer. The effect of activity was also significant $\left(F_{3,81}=22.0, p<0.0001\right)$, and interindividual distance was smallest in "both resting or grooming," intermediate in "both foraging" and "other combinations", and largest in "either or both moving." The effect of kinship was not significant $\left(F_{1,35}=0.03, p=0.87\right.$, Fig. 2$)$. We found a significant interaction between season and activity $\left(F_{6,81}=3.0, p=0.01\right)$. Therefore, we conducted simple main effect tests by season and activity. Intraseason differences in activity were highly significant in each season (autumn, $F_{3,81}=9.9, p<0.0001$; winter, $F_{3,81}=20.4, p<0.0001$; summer, $F_{3,81}=6.8, p=$ $0.0004)$. Intra-activity differences were relatively small in "both resting or grooming" $\left(F_{2,81}=\right.$ $4.7, p=0.01)$, and large in "both foraging" $\left(F_{2,81}=26.2, p<0.0001\right)$, "either or both moving" $\left(F_{2,81}=21.1, p<0.0001\right)$, and "other combinations" $\left(F_{2,81}=21.5, p<0.0001\right)$. Interindividual distances in all 3 seasons were shortest when the macaques were resting/grooming and longest when they were moving (Fig. 3). The relationship between foraging distance and distance during other activities differed among seasons: Foraging distances were as short as resting distances in autumn and summer, and as long as moving distances in winter. The proportion of time spent in each activity also varied among seasons (Table I).

Proximity and Interindividual Distance

For all seasons, the number of individuals differed significantly among distance categories (autumn, $F_{3,95}=24.6, p=0.03$; winter $F_{6,169}=10.8, p<0.0001$; summer, $F_{7,105}=3.1, p=$ 0.006) and was the largest at interindividual distances of $0-20 \mathrm{~m}$ and second largest at distances of $20-40 \mathrm{~m}$. The numbers of individuals were similar at distances $\geq 40 \mathrm{~m}$. In autumn and winter, the number of individuals was significantly larger at distances of $0-20$ 
$\mathrm{m}$ than in the other distance categories (Fig. 4A and 4B). In summer, we found a significant difference only between the largest mean at a distance of 0 to $20 \mathrm{~m}$ and the smallest mean at a distance of $60-100 \mathrm{~m}$ (Fig. 4C).

Proximity in Foraging and Food Type

Number of individuals within close proximity, i.e., $\leq 20 \mathrm{~m}$, while foraging was significantly affected by season, food type and interaction between season and food type (season: $F_{2,12}=$ 5.9, $p=0.02$; food type: $F_{1,10}=30.7, p=0.0002$; interaction: $F_{2,12}=4.4, p=0.04$, Fig.5).

Main effect tests revealed that during foraging on clumped food, the number of individuals in proximity did not differ among seasons $\left(F_{2,12}=1.4, p=0.29\right)$. During foraging on scattered food, the number of individuals was larger in autumn and in winter than in summer $\left(F_{2,12}=8.8, p=0.005\right)$. The number of individuals was greater during foraging on clumped food than scattered food during autumn $\left(F_{1,12}=6.1, p=0.03\right)$ and $\operatorname{summer}\left(F_{1,12}=\right.$ $28.1, p=0.0002)$ but did not differ in winter $\left(F_{1,12}=4.0, p=0.07\right)$.

Table II shows the percentage of time spent foraging by food type. In autumn, the macaques spent the largest proportion of the total foraging time on clumped food, which were mostly fruits and seeds of tree species. In winter, they spent the largest proportion on scattered food, which was mostly roots and/or leaves of tiny herbs. In summer, the animals foraged variety of food types.

\section{Discussion}

GPS Measurement of Interindividual Distance and Its Variations 
Our findings revealed considerable variation in interindividual spacing within a single group of Japanese macaques. This indicates that the animals can adjust group cohesiveness flexibly. This result is consistent with the recent suggestion that group aggregation patterns are variable within a species (Karczmarski et al., 2005; Yamagiwa, 1999) and within a group (Strier, 1989; Strier et al., 1993).

Interindividual distance has been considered as an index of cohesiveness (e.g., Semeniuk \& Dill 2002; Rolando et al. 2001, Irwin 2007). Interindividual distance in the present study, at least that of nonkin pairs, represented the distance between 2 random adult females in a group. Japanese macaques form female-bonded groups; adult females are thought to be located in the central zone of the group, while young or immigrant males are located the peripheral zone (Itani, 1954; Wada \& Matsuzawa, 1986). Thus, interindividual distance measured in the present study can be considered an index of cohesiveness among female group members, which likely form the central zone of the group.

Basic Pattern of Interindividual Spacing among Japanese Macaques

Group cohesion changed over short time periods within this group of Japanese macaques. The interindividual distribution curves of each season were skewed to the right and had a single peak, at least in autumn and winter. If 2 individuals are located independently within a constant circular area characterized by a homogeneous individual density, their interindividual distance will be distributed symmetrically around the peak of the circle's radius. In contrast, if 2 individuals start at the same location, e.g., a resting site or food patch, and move independently for a period of time, the distribution of their interindividual distance will be skewed to the right. Similarly, if 2 individuals start at 2 separate locations and move toward a 
joint (new) location, the distribution of their interindividual distance would also be skewed to the right. The distribution we found is consistent with the latter 2 possible processes.

Our findings regarding differences in interindividual distance among activities are also consistent with this view. Generally, the group became cohesive when they were resting and grooming, intermediate when foraging, and dispersed when moving. Movement led to greater interindividual distances. Group members appeared to spread out during travel between grooming sites and/or food patches. It is logical that distances between individuals would become longer as they moved faster, similar to the process of diffusion.

Food Resources and Group Cohesiveness

The nature of food resources is one of the most likely explanations for cohesiveness in Japanese macaques. The macaques became closer during resting and grooming in all seasons, but dispersed during foraging to different degrees among seasons. Food conditions are generally good in spring and autumn and poor in winter and summer for Japanese macaques (Hanya, 2010). Energy intake varies seasonally in our study population; being much larger in spring and autumn than in winter and summer (Nakagawa, 1997). Our results also revealed that the macaques ate foods that are distributed differently during the 3 seasons. Two aspects of food distribution may explain group cohesiveness: the availability of clumped food and the density of scattered food.

Larger numbers of group members aggregated around clumped food than scattered food. Individuals foraged on foods clumped in trees, such as fruits and seeds, more frequently in autumn than in other seasons. In contrast, they fed less frequently on clumped food in winter and summer, resulting in the aggregation of fewer group members during foraging. The positive relationship between the availability of clumped food and group cohesiveness may 
parallel those between food patch size and subunit size observed in species that show high fission-fusion dynamics (Janson, 1988; Shimooka, 2003; Strier, 1989; Symington, 1988), and in species showing low fission-fusion dynamics (van Schaik \& van Noordwijk, 1986; Whitten, 1988).

The availability of clumped food does not entirely account for differences in group cohesiveness between winter and summer. The overall mean number of individuals close to the foraging females for all food types did not differ between these seasons (Sugiura et. al., unpublished data). Moreover, the macaques foraged clumped food more frequently in summer than in winter, and the number of group members aggregated in clumped food sources was as large as in autumn. Therefore, the effects of scattered food, which accounts for $85.0 \%$ of total foraging time in winter and $62.7 \%$ of that time in summer, must also be taken into consideration.

In winter, the macaques mostly fed on the roots and/or leaves of small plants. These plants appear to be relatively uniformly and densely distributed, because the macaques moved slowly while foraging on them continuously. Once they had foraged a given site, they moved only a few meters to search for further plants. That is, they appeared to adopt a low-cost/lowyield tactic, moving minimal distances to obtain very small amounts of food. Such slow movement may have prevented the group members from dispersing widely.

In summer, the macaques fed on higher quality and more sparsely scattered food, such as fungi and the leaves and fruits of vines. They moved long distances while searching for such foods (Sugiura et. al., unpublished data). That is, they appeared to adopt a high-cost/highyield tactic. Such rapid movement while searching for scattered food is likely to lead to low group cohesiveness. In addition, the location of fungi is usually difficult to predict and the quantity is usually too small to share. Foraging on such unpredictable foods may have created unpredictable traveling patterns among individuals, resulting in a more scattered distribution 
of group members.

Food Resources and Social Interactions

Affiliative social interaction has been noted as a major reason for group cohesiveness since the early stages of primatology (Baldwin \& Baldwin, 1972; Itani, 1954). Our study revealed that group cohesiveness was highest when the macaques were resting and grooming. Group members may come closer for affiliative social interaction. Close cohesion is likely to facilitate more efficient interaction among many group members. Relatively longer grooming times in autumn may have increased group cohesiveness relative to other seasons. The longer grooming time is likely to be a result of abundant food resources in autumn, because a tradeoff between the times for grooming and feeding has been suggested in Japanese macaques (Agetsuma \& Nakagawa, 1998). In contrast, poor food resources increased foraging time and resulted in shorter grooming time in winter and summer. Because time allocated to social interaction can partly depend on food conditions we cannot completely separate the factors of food resource and social interactions.

The Effect of Kinship

Japanese macaques are female bonded and nepotistic (Matsumura, 2001) and many studies of Japanese macaques have reported the effects of kinship on close proximity (e.g., Nakamichi \& Yamada, 2010). However, we found no differences in interindividual distances between kin and non-kin pairs. Kin pairs of adult females probably do not always maintain close distances, but do so in limited situations, such as affiliative or competitive situations, when close proximity to kin is favorable. The effects of kinship on interindividual distances may be 
detectable with additional data and a finer classification of social situations, e.g., social grooming as an affiliative situation and feeding on clumped food with many group members together as a competitive situation. This effect may also be detectable if we include juveniles, e.g., mother - juvenile offspring or adult - juvenile sisters. Juveniles are vulnerable to competition and keeping close distance to kin individual is likely to be more beneficial than adult females.

Predation Avoidance

Predation avoidance is a major factor for group aggregation (Sterck et al., 1997). However, predation pressure was negligible in this study, and individuals did not need to cohere to avoid predation. The population at this study site had no natural predators. Moreover, Japanese macaques are relatively large: adult females weigh $7-10 \mathrm{~kg}$ (Kurita et al., 2002) and, despite the vast quantity of observational data for this species (Nakagawa et al., 2010), reports of predation on Japanese macaques are quite limited (Iida, 1999). Predation-free conditions may have increased the variation in spacing for this group, although they do respond appropriately to threats, such as dogs.

Subgrouping

Subgrouping occurred temporarily in our study group. Because the majority of our study group's habitat was mountainous forest, the focal animals were thus likely unable to monitor other subgroup(s) when they were separated by distances of a few hundred meters or more and were therefore unable to match their movements. The number of individuals within $20 \mathrm{~m}$ of the focal animals was similar regardless of the distance between the 2 focal animals, except 
for short distances of 0 to $40 \mathrm{~m}$ in summer. This is consistent with the view that the group is split into 2 (or a few) subunits that move collectively with group members.

We only detected subgrouping in summer, when interindividual spacing was usually long and movement was fast. Thus, formation of these subgroups may be accidental, not intentional. According to the "fission-fusion dynamics" concept (Aureli et al., 2008), Japanese macaques show intermediate fission-fusion dynamics. However, their behavior related to group cohesiveness may differ qualitatively from species showing high fissionfusion dynamics.

Implications for Group Coordination and Decision Making

Group cohesiveness influences group coordination. Individuals of a very cohesive group must choose the same travel routes and the same food patches as the other members. In contrast, individuals of less cohesive groups can choose food patches and travel routes relatively freely (Jacobs, 2010). In fact, 2 individual Japanese macaques occasionally took different paths while traveling (Sugiura, unpublished data). Japanese macaques form relatively large groups with ca. 10 to 150 individuals of different ages and sexes (Yamagiwa \& Hill, 1998). Relatively large spacing among group members may help to meet the different demands of heterogeneous group members. The number of animals in proximity during foraging was small, especially when they foraged scattered food, which supports this view.

Group cohesiveness also influences communication among group members, which is an important element for collective decision making (Conradt \& Roper, 2005). Japanese macaques do not have a loud vocalization (Green, 1975; Itani, 1963), and their most common call — the coo call (Sugiura, 1993) - is usually exchanged within a distance of 10 to $30 \mathrm{~m}$ (Okayasu, 1987). Visibility is also limited in forests, where they usually range. In the present 
population, the average visible distance is 30 to $50 \mathrm{~m}$ (Koda et al., 2008). Thus, it is safe to say that their usual communicable range is roughly $50 \mathrm{~m}$ at the most. Interindividual distance often exceeded this distance. Their communication likely usually occurred locally with some group members, rather than globally with all group members. In addition, the number of individuals within communication range changed with activities and seasons, as interindividual distances changed. Such dynamic changes in cohesiveness may influence the achievement and occurrence of decision making by whole groups, or subgroups.

\section{Acknowledgements}

We thank Professor Kosei Izawa for supporting the overall research activities on Kinkazan Island, the staff at Kinkazan Koganeyama Shrine for the use of its facilities, and Ms. Yoko Sugiura for data collection. We thank Drs. Andrew J. King, Cédric Sueur, Peter Henzi, Joanna M. Setchell, and an anonymous reviewer for valuable comments. This work was supported by a Grant-in-Aid for Scientific Research (C, \#22570219) from JSPS to SH, a Grant for Biodiversity Research of the 21st Century COE (A14), and a Grant for Biodiversity and Evolutionary Research of the Global COE (A06) to Kyoto University. 


\section{References}

Agetsuma, N., \& Nakagawa, N. (1998). Effects of habitat differences on feeding behaviors of Japanese monkeys: Comparison between Yakushima and Kinkazan. Primates, 39, 275289.

Aureli, F., Schaffner, C. M., Boesch, C., Bearder, S. K., Call, J., Chapman, C. A., et al. (2008). Fission-fusion dynamics: New research frameworks. Current Anthropology, 49, $627-654$.

Baldwin, J. D., \& Baldwin, J. (1972). The ecology and behavior of squirrel monkeys (Saimiri oerstedi) in natural forest in western Panama. Folia Primatologica, 18, 161-184.

Bezanson, M., Garber, P. A., Murphy, J. T., \& Premo, L. S. (2008). Patterns of subgrouping and spatial affiliation in a community of mantled howling monkeys (Alouatta palliata). American Journal of Primatology, 70, 282-293.

Boinski, S. (1987). Habitat use by squirrel monkeys (Saimiri oerstedi) in Costa Rica. Folia Primatologica, 49, 151-167.

Chapais, B., Gauthier, C., PrudHomme, J., \& Vasey, P. (1997). Relatedness threshold for nepotism in Japanese macaques. Animal Behaviour, 53, 1089-1101.

Chivers, D. P., Brown, G. E., \& Smith, R. J. F. (1995). Familiarity and shoal cohesion in fathead minnows (Pimephales promelas) - implications for antipredator behavior. Canadian Journal of Zoology, 73, 955-960.

Conradt, L., \& Roper, T. J. (2005). Consensus decision making in animals. Trends in Ecology \& Evolution, 20, 449-456.

D'Eon, R. G., \& Delparte, D. (2005). Effects of radio-collar position and orientation on GPS radio-collar performance, and the implications of PDOP in data screening. Journal Of Applied Ecology, 42, 383-388. 
Goodall, J. (1986). Social rejection, exclusion, and shunning among the Gombe chimpanzees. Ethology and Sociobiology, 7, 227-236.

Green, S. (1975). Variation of vocal pattern with social situation in the Japanese monkey (Macaca fuscata): A field study. In L. A. Rosenblum (Ed.), Primate Behavior (Vol. 4, pp. 1-102). New York: Academic Press.

Hamilton, W. D. (1971). Geometry for selfish herd. Journal of Theoretical Biology, 31, 295311.

Hanya, G. (2010). Ecological adaptations of temperate primates: Population density of Japanese macaques. In N. Nakagawa, M. Nakamichi \& H. Sugiura (Eds.), The Japanese Macaques. Tokyo: Springer.

Hashimoto, C., Suzuki, S., Takenoshita, Y., Yamagiwa, J., Basabose, A. K., \& Furuichi, T. (2003). How fruit abundance affects the chimpanzee party size: a comparison between four study sites. Primates, 44, 77-81.

Hayakawa, S. (2007). Female defensibility in small troops of Japanese macaques vis-a-vis nontroop males and copulation on the periphery of the troop. International Journal of Primatology, 28, 73-96.

Hill, D. A., \& Okayasu, N. (1995). Absence of "youngest ascendancy" in the dominance relations of sisters in wild Japanese macaques (Macaca fuscata yakui). Behaviour, 132, 367-379.

Iida, T. (1999). Predation of Japanese macaque Macaca fuscata by mountain hawk eagle Spizaetus nipalensis. Japanese Journal of Ornithology, 47, 125 - 127.

Irwin, M. T. (2007). Living in forest fragments reduces group cohesion in diademed sifakas (Propithecus diadema) in eastern Madagascar by reducing food patch size. American Journal of Primatology, 69, 434-447. 
Itani, J. (1954). The monkeys of Mt. Takasaki (in Japanese) (Imanishi, K. ed.). Tokyo:

Kobunsha.

Itani, J. (1963). Vocal communication of the wild Japanese monkey. Primates, 4, 11-66.

Izawa, K. (2009). Studies of wild Japanese macaques (in Japanese). Tokyo: Dobutsusha.

Jacobs, A. (2010). Group cohesiveness during collective movements: Travelling apart together. Behavioural Processes, 84, 678-680.

Janson, C. H. (1988). Intra-specific food competition and primate social structure: A synthesis. Behaviour, 105, 1-17.

Janson, C. H. (1990a). Ecological consequences of individual spatial choice in foraging groups of brown capuchin monkeys, Cebus apella. Animal Behaviour, 40, 922-934.

Janson, C. H. (1990b). Social correlates of individual spatial choice in foraging groups of brown capuchin monkeys, Cebus apella. Animal Behaviour, 40, 910-921.

Karczmarski, L., Wursig, B., Gailey, G., Larson, K. W., \& Vanderlip, C. (2005). Spinner dolphins in a remote Hawaiian atoll: social grouping and population structure. Behavioral Ecology, 16, 675-685.

Koda, H., Shimooka, Y., \& Sugiura, H. (2008). Effects of caller activity and habitat visibility on contact call rate of wild Japanese macaques (Macaca fuscata). American Journal of Primatology, 70, 1055-1063.

Koyama, N. (1967). On dominance rank and kinship of a wild Japanese monkey troop in Arashiyama. Primates, 8, 189-216.

Kummer, H. (1971). Primate societies: Group techniques of ecological adaptation. Chicago: Aldine.

Kurita, H., Shimomura, T., \& Fujita, T. (2002). Temporal variation in Japanese macaque bodily mass. International Journal of Primatology, 23, 411-428. 
Matsumoto-Oda, A., Hosaka, K., Huffman, M. A., \& kawanaka, K. (1998). Factors affecting party size in chimpanzees of the Mahale Mountains. International Journal of Primatology, 19, 999-1011.

Matsumura, S. (2001). The myth of despotism and nepotism: Dominance and kinship in matrilineal societies of macaques. In T. Matsuzawa (Ed.), Primate origins of human cognition and behavior (pp. 441-462). Tokyo: Springer Verlag.

Nakagawa, N. (1997). Determinants of the dramatic seasonal changes in the intake of energy and protein by Japanese monkeys in a cool temperate forest. American Journal of Primatology, 41, 267-288.

Nakagawa, N., Nakamichi, M., \& Sugiura, H. (Eds.). (2010). The Japanese Macaques. Tokyo: Springer.

Nakamichi, M., \& Yamada, K. (2010). Lifetime social development in female Japanese macaques. In N. Nakagawa, M. Nakamichi \& H. Sugiura (Eds.), The Japanese Macaques (pp. 241-270). Tokyo: Springer.

Nishida, T. (1968). The social group of wild chimpanzees in the Mahali Mountains. Primates, 9, 167-224.

Okayasu, N. (1987). Coo sound communication (in Japanese). Quaternary Anthropology, 19, $12-30$.

Robinson, J. G. (1981). Spatial structure in foraging groups of wedge-capped capuchin monkeys Cebus nigrivittatus. Animal Behaviour, 29, 1036-1056.

Rolando, A., Caldoni, R., De Sanctis, A., \& Laiolo, P. (2001). Vigilance and neighbour distance in foraging flocks of red-billed choughs, Pyrrhocorax pyrrhocorax. Journal of Zoology, 253, 225-232.

Sato, S. (1988). Monkeys of the Kinkazan A group (in Japanese). Japanese Monkeys in Miyagi Prefecture, 3, 6-29. 
Semeniuk, C. A. D., \& Dill, L. M. D. (2002). Costs and benefits of grouped and solitary resting in the cowtail stingray, Pastinachus sephen, in Shark Bay, Western Australia. Integrative and Comparative Biology, 42, 1309-1309.

Shimooka, Y. (2003). Seasonal variation in association patterns of wild spider monkeys (Ateles belzebuth belzebuth) at La Macarena, Colombia. Primates, 44, 83-90.

Sibly, R. M., Nott, H. M., \& Fletcher, D. J. (1990). Splitting behaviour into bouts. Animal Behaviour, 39, 63-69.

Slater, P. J., \& Lester, N. P. (1982). Minimising errors in splitting behaviour into bouts. Behaviour, 79, 153-161.

Sterck, E. H. M., Watts, D. P., \& vanSchaik, C. P. (1997). The evolution of female social relationships in nonhuman primates. Behavioral Ecology and Sociobiology, 41, 291-309.

Strier, K. B. (1989). Effects of patch size on feeding associations in muriquis (Brachyteles arachnoides). Folia Primatologica, 52, 70-77.

Strier, K. B. (1992). Atelinae adaptations - behavioral strategies and ecological constraints. American Journal of Physical Anthropology, 88, 515-524.

Strier, K. B., Mendes, F. D., Rimoli, J., \& Rimoli, A. O. (1993). Demography and social structure of one group of muriquis (Brachyteles arachnoides). International Journal of Primatology, 14, 513-526.

Sueur, C., Petit, O., \& Deneubourg, J. L. (2010). Short-term group fission processes in macaques: a social networking approach. Journal of Experimental Biology, 213, 13381346.

Sugiura, H. (1993). Temporal and acoustic correlates in vocal exchange of coo calls in Japanese macaques. Behaviour, 124, 207-225.

Sugiyama, Y., \& Ohsawa, H. (1982). Population dynamics of Japanese macaques at Ryozenyama: III. Female desertion of the troop. Primates, 23, 31-44. 
Symington, M. M. (1988). Food competition and foraging party size in the black spider monkey (Ateles paniscus chamek). Behaviour, 105, 117-134.

Tsuji, Y., Fujita, S., Sugiura, H., Saito, C., \& Takatsuki, S. (2006). Long-term variation in fruiting and the food habits of wild Japanese macaques on Kinkazan island, northern Japan. American Journal of Primatology, 68, 1068-1080.

Tsuji, Y., \& Takatsuki, S. (2004). Food habits and home range use of Japanese macaques on an island inhabited by deer. Ecological Research, 19, 381-388.

van Schaik, C. P., \& van Noordwijk, M. A. (1986). The hidden costs of sociality: Intra-group variation in feeding strategies in Sumatran long-tailed macaques (Macaca fascicularis). Behaviour, 99, 296-315.

Wada, K., \& Matsuzawa, T. (1986). A new approach to evaluating troop deployment in wild Japanese monkeys. International Journal of Primatology, 7, 1.

Waser, P. M. (1984). "Chance" and mixed-species associations. Behavioral Ecology and Sociobiology, 15, 197-202.

Whitesides, G. H., Oates, J. F., Green, S. M., \& Kluberdanz, R. P. (1988). Estimating primate densities from transects in a West-African rain-forest - a comparison of techniques. Journal of Animal Ecology, 57, 345-367.

Whitten, P. L. (1988). Effects of patch quality and feeding subgroup size on feeding success in vervet monkeys (Cercopithecus Aethiops). Behaviour, 105, 35-52.

Wrangham, R. W. (1980). An ecological model of female-bonded primate groups. Behaviour, $75,262-300$.

Yamagiwa, J. (1999). Socioecological factors influencing population structure of gorillas and chimpanzees. Primates, 40, 87-104. 
Yamagiwa, J., \& Hill, D. A. (1998). Intraspecific variation in the social organization of Japanese macaques: Past and present scope of field studies in natural habitats. Primates, $39,257-273$. 
Table I. Mean \pm SE individual daily activity budgets

\begin{tabular}{lccc}
\hline & Autumn (\%) & Winter (\%) & Summer (\%) \\
\hline Grooming & $18.87 \pm 1.87$ & $13.22 \pm 1.46$ & $10.36 \pm 1.61$ \\
Resting & $13.80 \pm 0.90$ & $7.94 \pm 1.05$ & $18.90 \pm 0.54$ \\
Foraging & $52.04 \pm 1.93$ & $69.26 \pm 2.20$ & $35.66 \pm 3.58$ \\
Moving & $14.93 \pm 0.67$ & $9.53 \pm 0.64$ & $35.03 \pm 2.69$ \\
Agonistic interaction & $0.36 \pm 0.07$ & $0.05 \pm 0.01$ & $0.05 \pm 0.02$ \\
\hline
\end{tabular}

Table II. Mean \pm SE proportion of time spent foraging by food type

\begin{tabular}{lccc}
\hline Food type & Autumn (\%) & Winter (\%) & Summer (\%) \\
\hline Clumped food & $\mathbf{7 9 . 0} \pm \mathbf{1 . 7}$ & $\mathbf{1 5 . 0} \pm \mathbf{3 . 1}$ & $\mathbf{3 7 . 3} \pm \mathbf{3 . 7}$ \\
Tree & $63.2 \pm 2.7$ & $14.6 \pm 3.0$ & $29.1 \pm 3.7$ \\
Shrub (Berberis thunbergii) & $0.2 \pm 0.1$ & $0.2 \pm 0.1$ & $8.1 \pm 1.9$ \\
Herb (Perilla frutescens) & $15.6 \pm 2.1$ & $0.1 \pm 0.1$ & $0.0 \pm 0.0$ \\
& & & \\
Scattered food & $\mathbf{2 1 . 0} \pm \mathbf{1 . 7}$ & $\mathbf{8 5 . 0} \pm \mathbf{3 . 1}$ & $\mathbf{6 2 . 7} \pm 3.7$ \\
Shrub & $16.8 \pm 1.7$ & $14.6 \pm 2.6$ & $2.8 \pm 0.9$ \\
Herb & $2.9 \pm 0.4$ & $61.8 \pm 4.4$ & $23.2 \pm 2.2$ \\
Vine & $0.1 \pm 0.1$ & $5.6 \pm 2.3$ & $20.2 \pm 4.4$ \\
Fungi & $0.8 \pm 0.2$ & $0.1 \pm 0.1$ & $15.2 \pm 3.1$ \\
Animal & $0.3 \pm 0.1$ & $0.5 \pm 0.2$ & $1.4 \pm 0.4$ \\
Seaweed & $0.0 \pm 0.0$ & $2.5 \pm 0.8$ & $0.0 \pm 0.0$ \\
\hline
\end{tabular}


Fig. 1. Distributions of interindividual distances in autumn (A), winter (B), and summer (C, D). (C) Overall distribution in summer and the fitted curves of the two-process model (thick line) and its two components of gamma distribution curves (thin lines). (D) Distributions in summer that were classified as non-subgrouping. Gamma distributions applied to the actual data in each season are shown, with means indicated by shaded triangles (A, B, D).

Fig. 2. Mean interindividual distances of $\operatorname{kin}(\mathrm{N}=32)$ and non-kin $(\mathrm{N}=5)$ pairs. Error bars show $95 \%$ confidence intervals of means.

Fig. 3. Mean interindividual distances by activity in 3 seasons. Error bars show $95 \%$ confidence intervals of means. Significant differences in posthoc pairwise comparisons were found between different labels (a and $\mathbf{b})$ or between pairs with connecting lines $(p<0.05)$.

Fig. 4. Mean number of individuals $\leq 20 \mathrm{~m}$ of focal females by the distance between the 2 focal animals. Error bars show 95\% confidence intervals of means. Significant differences in posthoc pairwise comparisons were found between different labels (a and $\mathbf{b}$ ) or between pairs with connecting lines $(p<0.05)$.

Fig. 5. Mean number of individuals $\leq 20 \mathrm{~m}$ of focal females during foraging of clumped and scattered foods. Error bars show 95\% confidence intervals of means. Significant differences of posthoc pairwise comparisons were found between pairs with connected lines within each season and between different characters (a and $\mathbf{b})$ within food category $(p<0.05)$. 


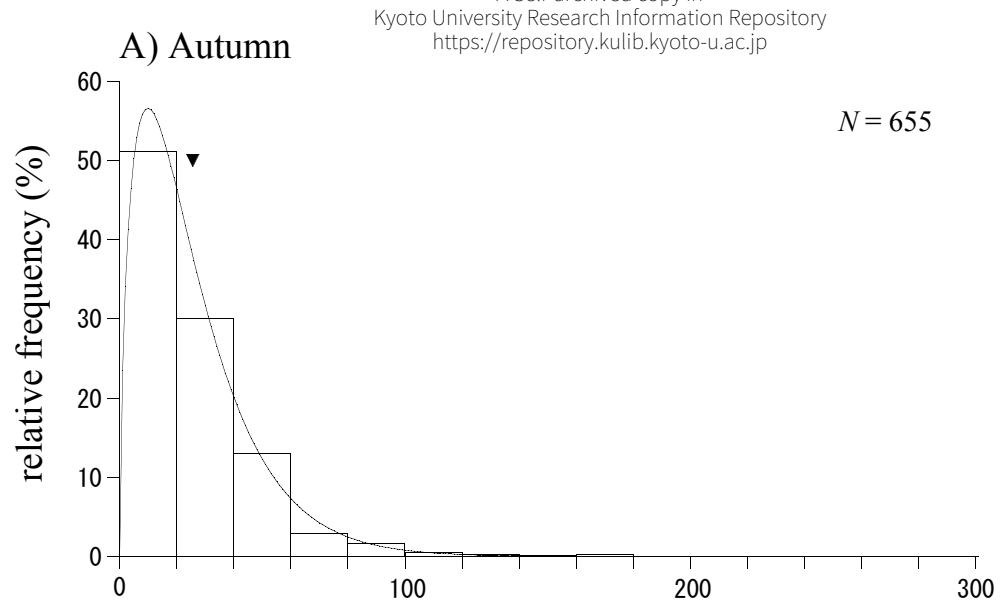

B) Winter

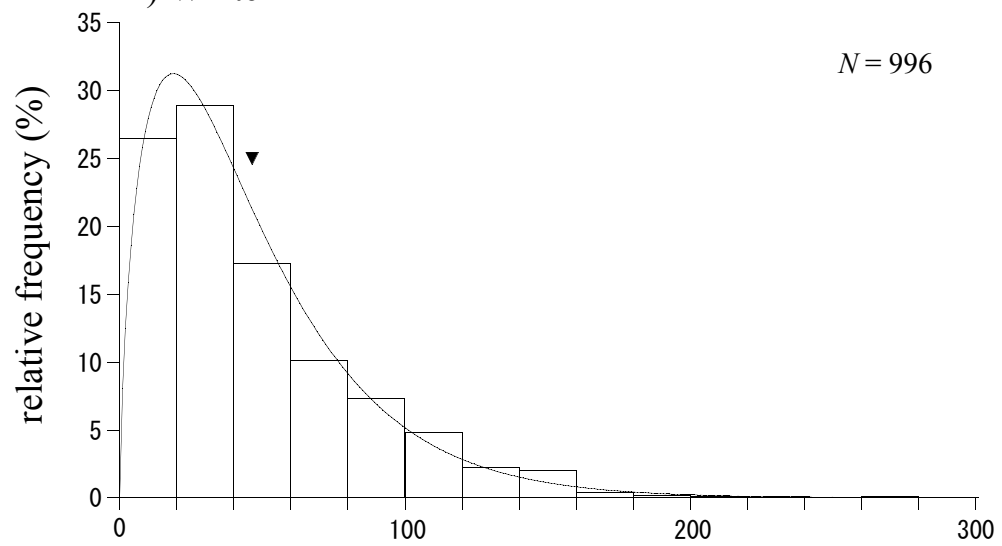

C) Summer (overall)

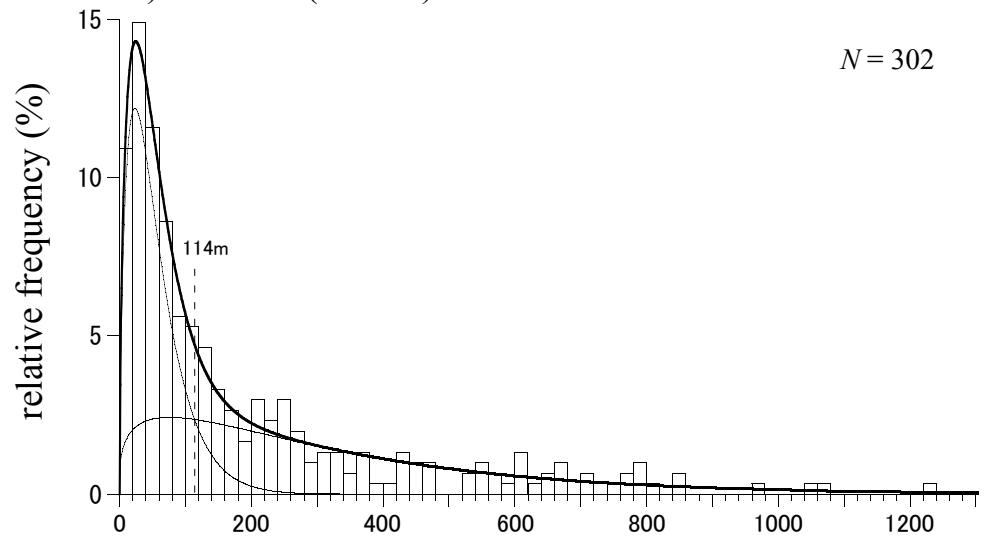

D) Summer (non-subgrouping)

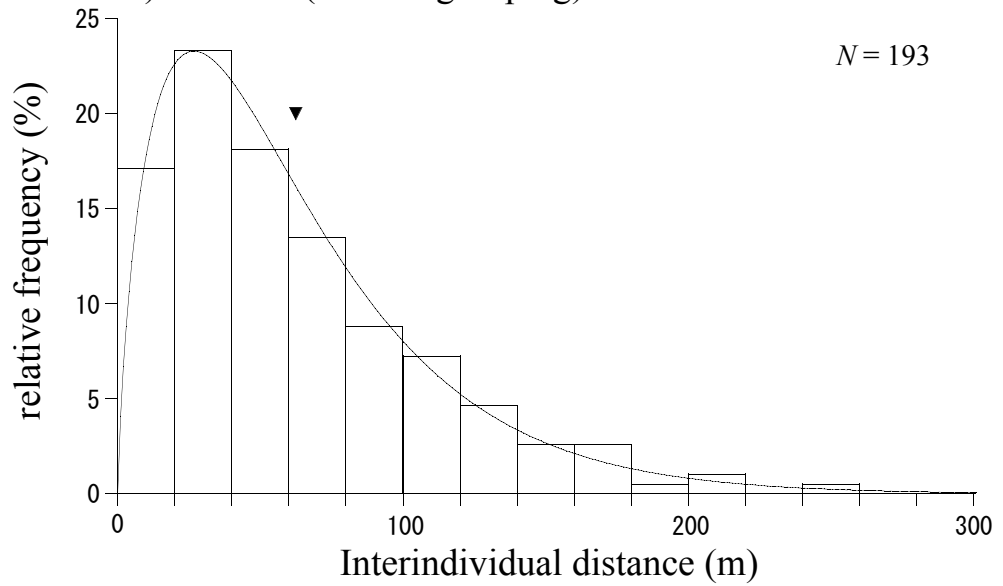




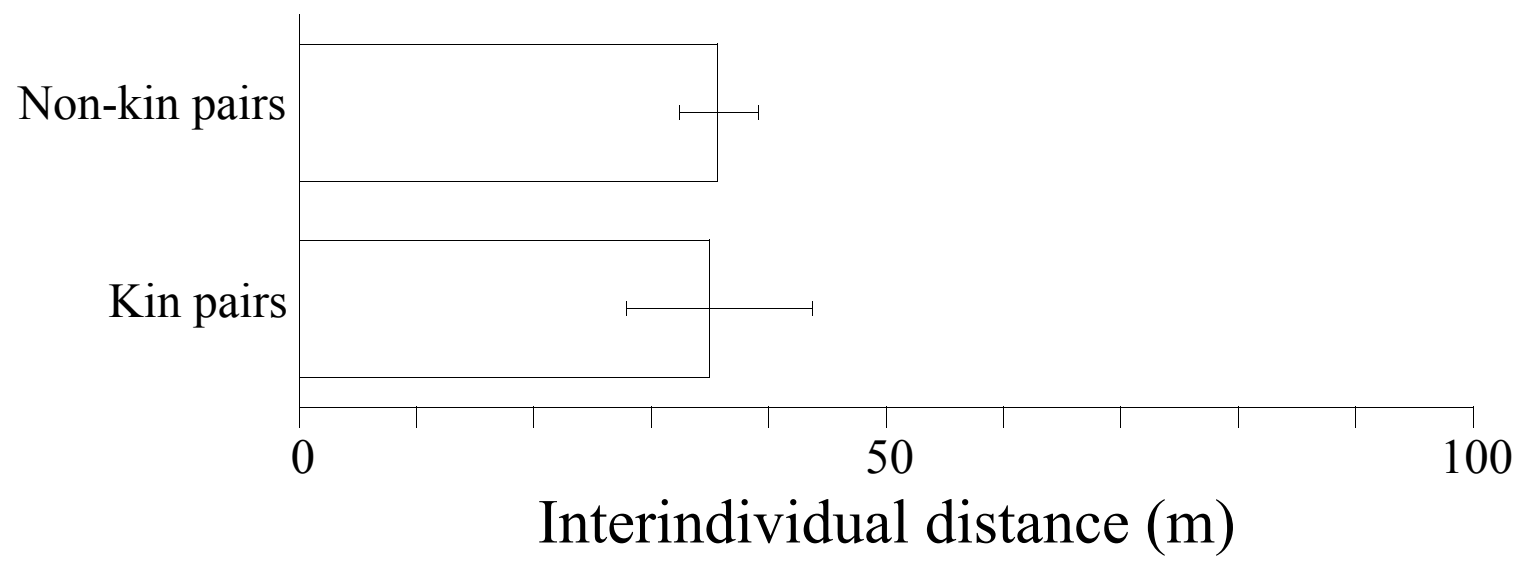

Figure 2 


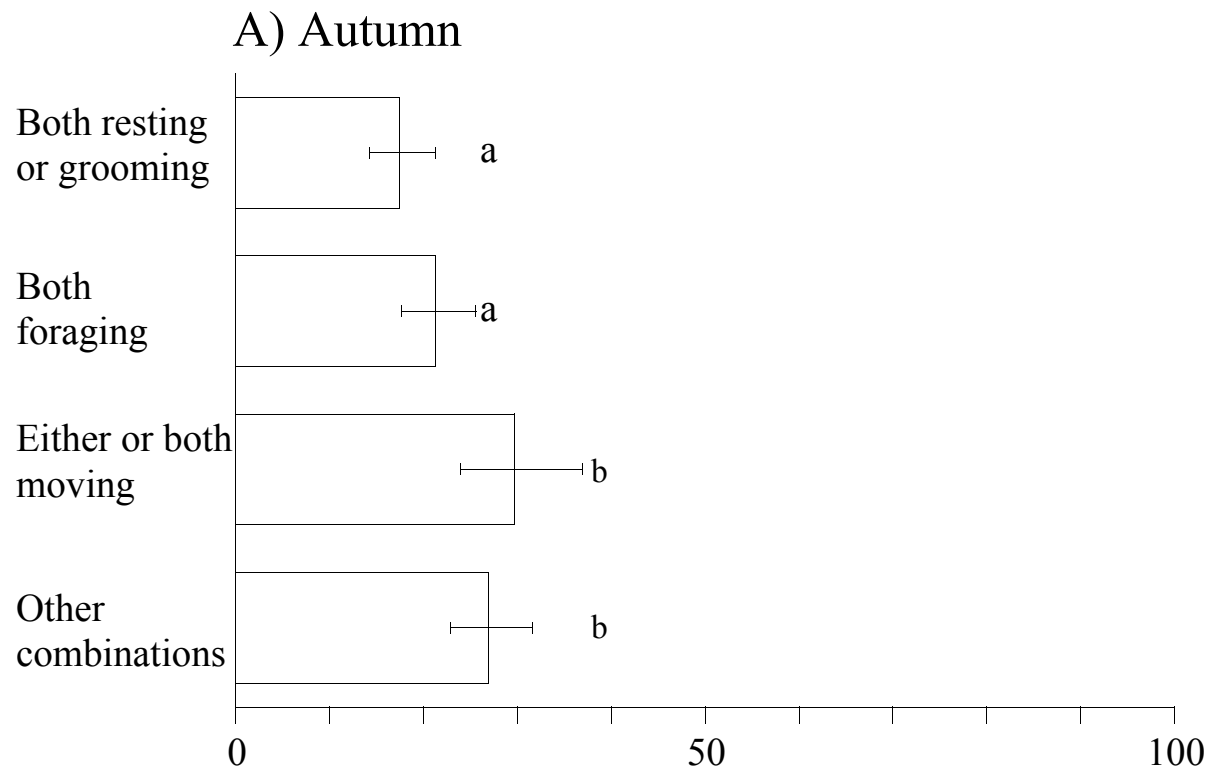

B) Winter

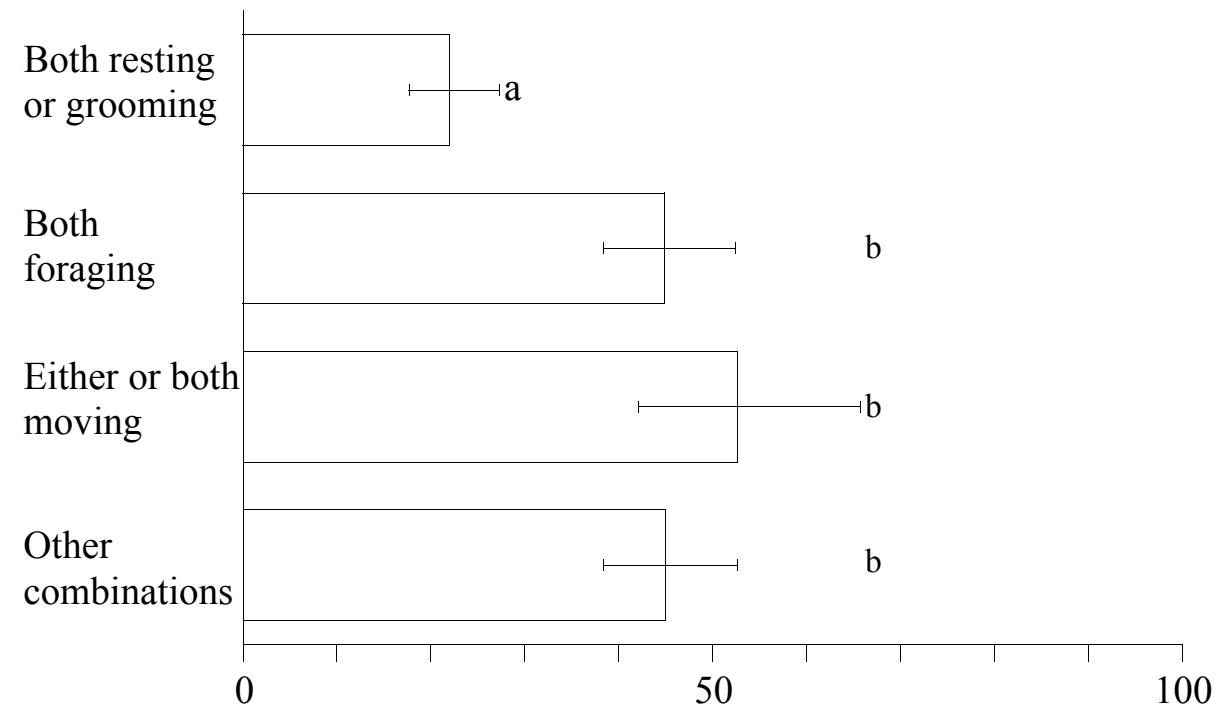

C) Summer (non-subgrouping)

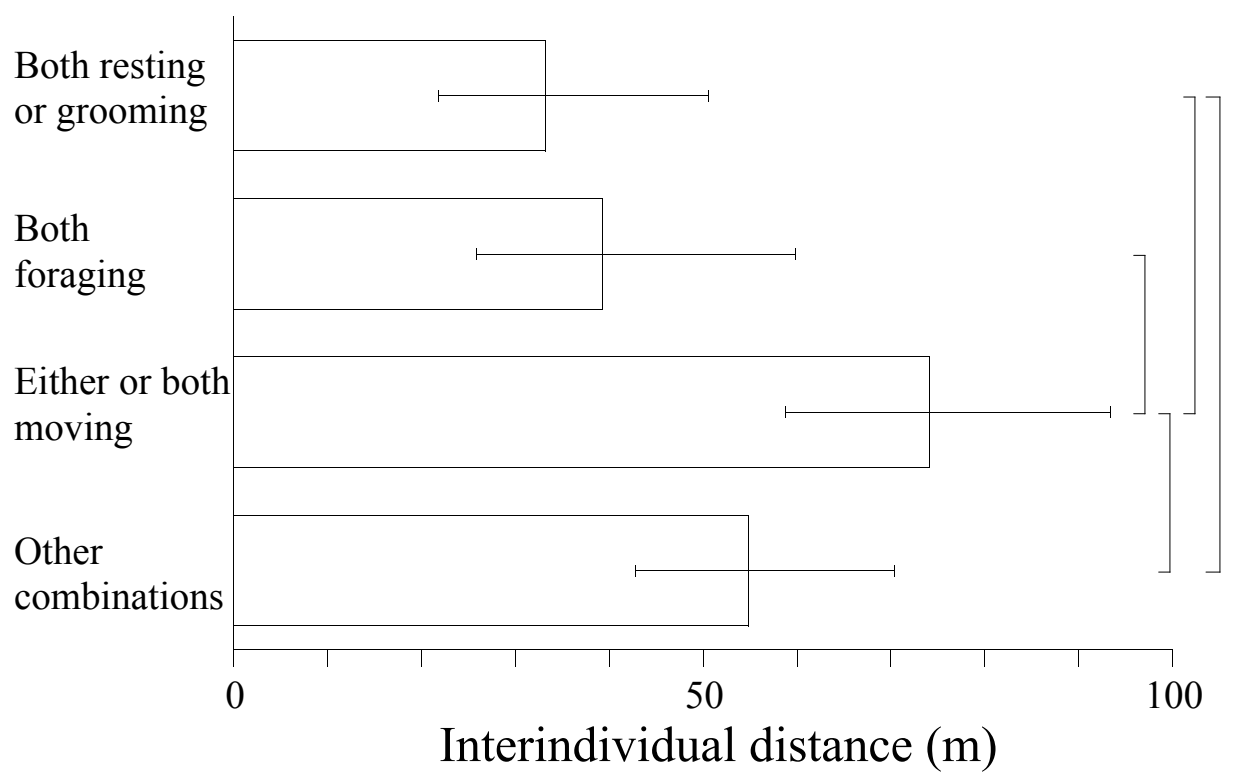

Figure 3 
A) Autumn

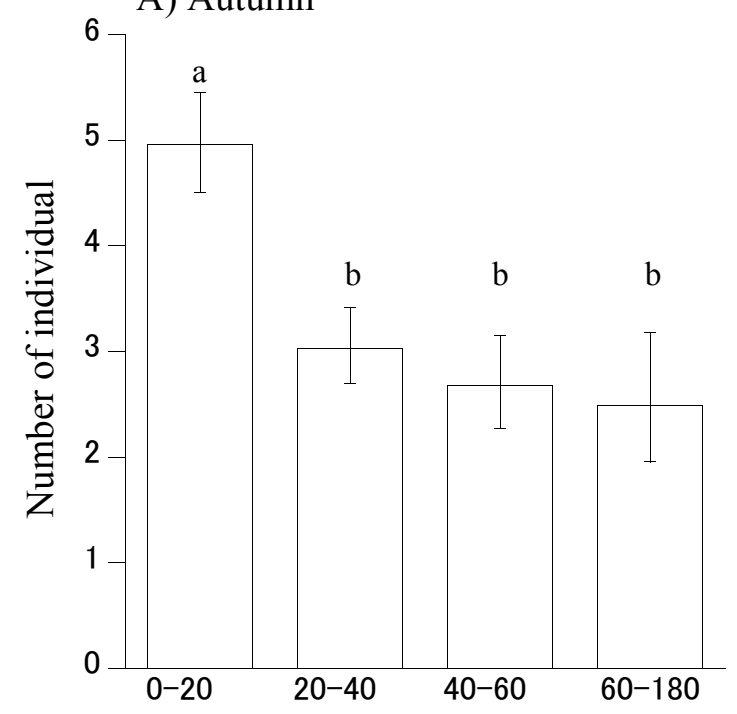

B) Winter

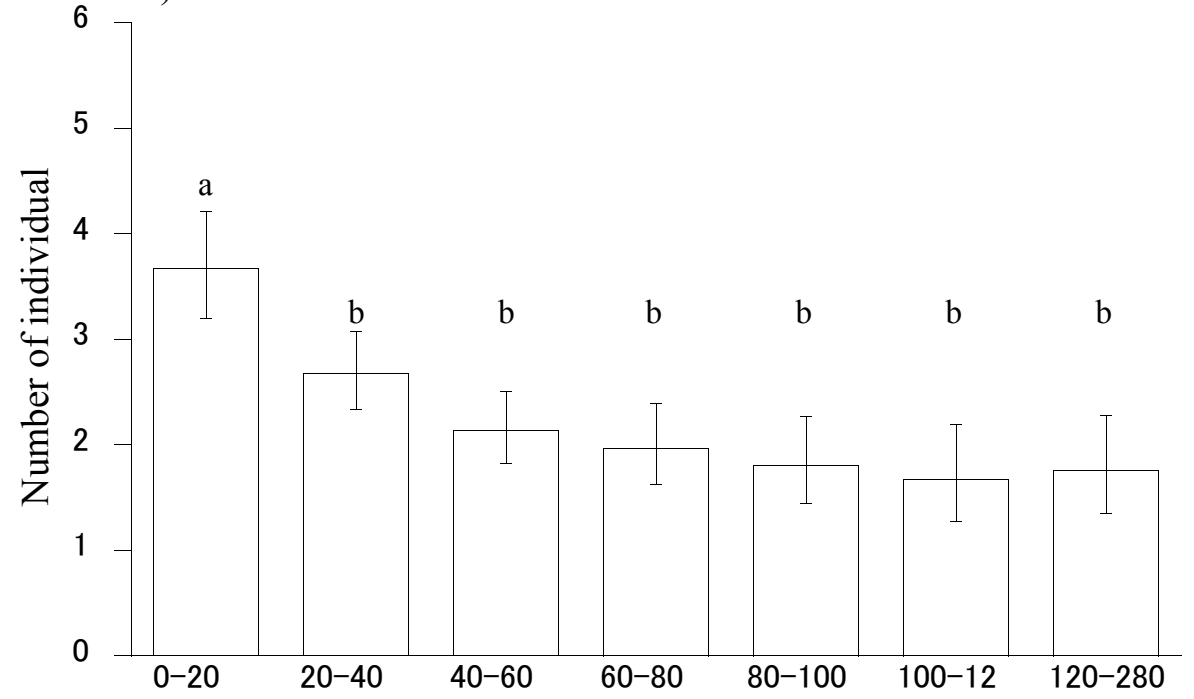

C) Summer

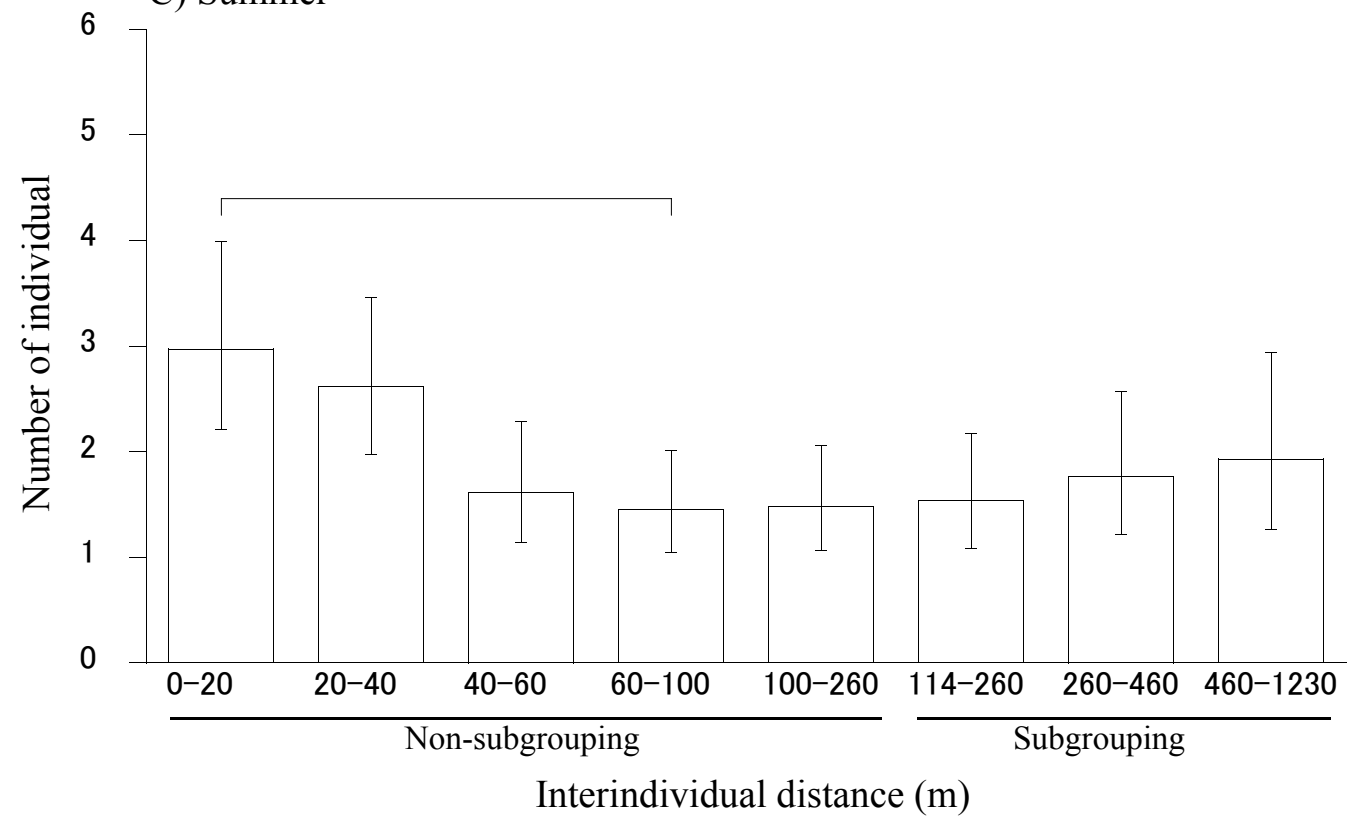

Fig. 4 


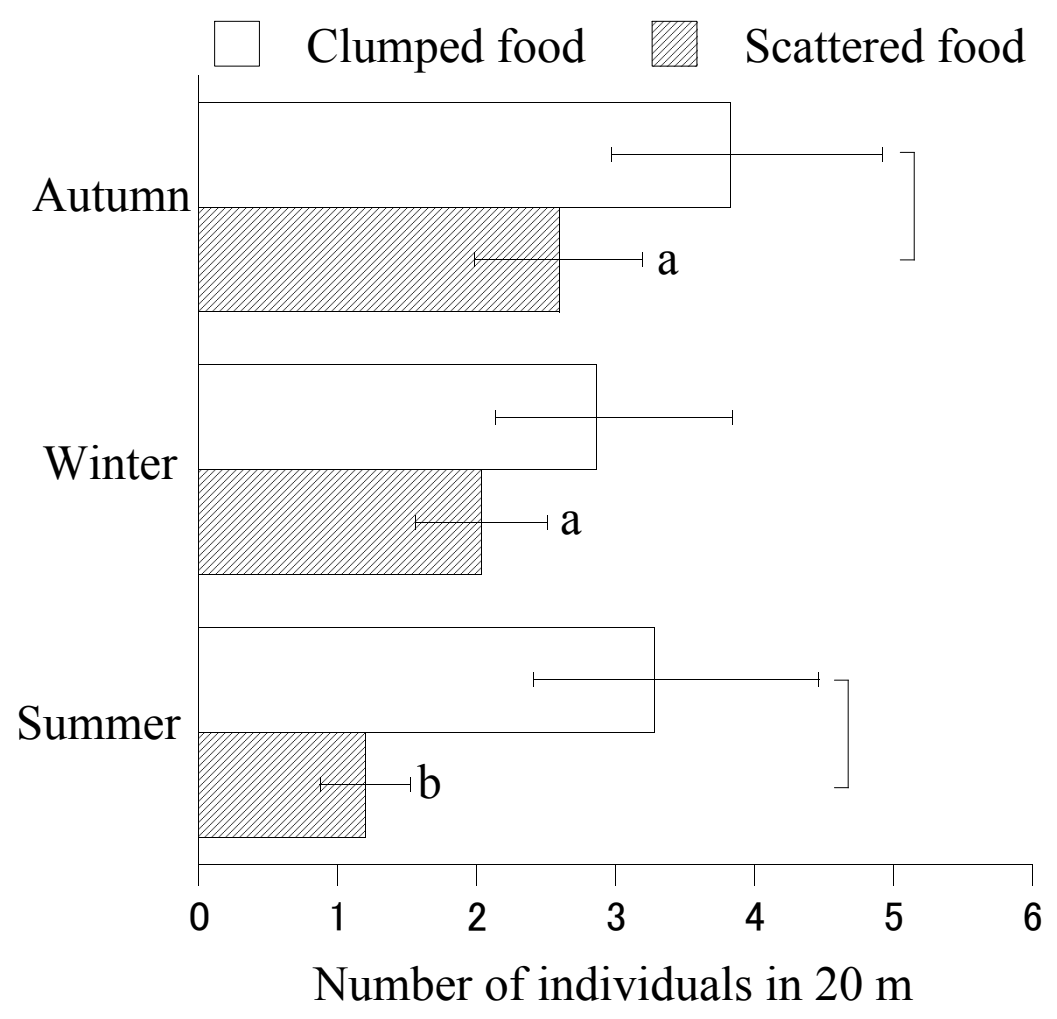

Figure 5 